\title{
MESIN ELUK BULU BAGI PENGRAJIN SHUTTLECOCK DESA PULESARI TIRTOMOYO, KECAMATAN PAKIS KABUPATEN MALANG
}

\author{
Wahju Wulandari ${ }^{1)}$, Sodik ${ }^{2}$ ), Dharmayanti Pri Handini ${ }^{3)}$ \\ Fakultas Ekonomi Universitas Widyagama Malang ${ }^{1,2,3)}$ \\ Email : ndari.sodik@yahoo.com ${ }^{1)}$
}

\begin{abstract}
ABSTRAK
Kegiatan pengabdian masyarakat dilakukan di sentra industri shuttlecock desa Pulesari Tirtomoyo kecamatan Pakis Kabupaten Malang. Pemilik usaha masih menggunakan alat sederhana, sehingga proses produksi lambat, tidak standart, produk masih banyak cacat, dan shuttlecock di pukul masih oleng. Tujuan pengabdian masyarakat, memberikan pemahaman tentang pentingnya memanfaatkan teknologi dengan membuatkan desain dan mesin eluk bulu angsa agar proses menjadi lebih efisien, cepat, akurasi pukulan sudah sesuai dengan standart. Metode pelaksanaan dengan memilih mitra dan sekaligus dilakukan kesepakatan mesin yang akan dibuat, membuatkan disain mesin eluk bulu angsa, mencari bengkel mesin, uji coba mesin dan praktek di tempat mitra, revisi mesin jika masih belum sempurna, dilakukan uji coba kembali dan penyerahan mesin ke mitra untuk dimanfaatkan sepenuhnya. Karya utama berupa desain mesin eluk bulu angsa, 1 unit mesin eluk bulu angsa yang digerakkan dengan dinamo listrik 1 pk, daya listrik 250 watt, voltase 220 . Hasil eluk bulu angsa lebih efisien dan efektif baik dari sis waktu, biaya tenaga kerja, dan hasil produksi lebih banyak dan strandart. Dampak bagi mitra sangat bermanfaat, karena proses pembuatan shuttle cock dimulai dari bulu angsa yang sudah dikukus dan dikeringkan kemudian dieluk satu per satu agar lurus masih dijalankan secara manual dengan berbekal tang saja dan perlu waktu yang cukup lama yaitu : 1 shuttle cock terdiri dari 16 bulu angsa diperlukan waktu $1 / 2$ menit atau dalam 1 menit menghasilkan 32 bulu angsa lurus. Mesin eluk bulu angsa sebagai teknologi tepat guna dalam 1 menit menghasilkan sebanyak 100 bulu atau \pm 8 slop shuttle cock, dan masih ada kelebihan 3 cock. 1 slop 12 shuttle cock dengan harga Rp. 54.000,- dan sisa 3 shuttle cock x Rp. $4.500=\mathrm{Rp} \mathrm{13.500,-} \mathrm{oleh} \mathrm{karena} \mathrm{itu} \mathrm{pemanfaatan} \mathrm{teknologi}$ mampu memberikan kemudahan bagi usaha kecil dalam meningkatkan usaha. Inovasi mesin eluk bulu angsa dapat memberikan efisiensi waktu dan biaya, sedangkan kenaikan hasil produksi shuttle cock dalam 1 menit sebesar $312,5 \%$.
\end{abstract}

Kata kunci: inovasi, mesin, efisiensi, bulu angsa, eluk bulu

\begin{abstract}
Community service activities were conducted in the shuttlecock industry center of Pulesari Tirtomoyo village, Pakis district, Malang regency. Business owners still use a simple tool, so the production process is slow, not standart, the product is still a lot of defects, and shuttlecock at still shaking. The purpose of community service, providing an understanding of the importance of utilizing technology by making design and machine feathers goose down so that the process becomes more efficient, faster, the accuracy of punch is in accordance with the standard. Method of execution by selecting partner and simultaneously executing machine agreement to be made, making engine design of goose down feather, looking for machine workshop, testing machine and practice at partner place, machine revision if still not perfect, test and machine delivery to partner to be fully utilized. This partners condusted to improve is the design of the goose down feather machine, 1 unit of goose down feather machine powered by a 1 pk electric dynamo, 250 watt power supply, 220 voltage. The results of goose feather is more efficient and effective both from time saving, labor cost, more production and strandart. Impact for partners is very useful, because the process of making the shuttle cock starting from goose feathers that have been steamed and dried and then dieluk one by one so straight still run manually with armed pliers only and need a long time that is: 1 shuttle cock consists of 16 feathers the goose takes $1 / 2$ minutes or in 1 minute produces 32 straight goose feathers. Goose down feather machine as the right technology in 1 minute produces 100 feathers or \pm 8 slop shuttle cock, and there is still excess 3 cock. 1 slop 12 shuttle cock for Rp. 54.000, - and the remaining 3 shuttle cockx $R p .4 .500=R p 13,500$, - therefore the use of technology can provide convenience for small businesses in increasing business. Innovation of the goose down machine can provide time and cost efficiency, while the increase of shuttle cock production in 1 minute is $312.5 \%$.
\end{abstract}

Keywords: innovation, machine, efficiency, goose feather, featherweight 
Wulandari, Mesin Eluk Bulu Bagi Pengrajin Shuttlecock..

\section{PENDAHULUAN}

Desa Pulesari Tirtomoyo Kecamatan Pakis Kabupaten Malang merupakan salah satu desa yang sebagian besar masyarakatnya mempunyai usaha membuat shuttlecock. Usaha shuttlecock sudah hampir 7 tahun dan dijalankan secara turun temurun. Jenis usaha shuttlecock dikategorikan sebagai industri rumahan atau handmade dimana banyak rumah tangga yang mempunyai usaha sama yaitu membuat shuttlecock. Industri shuttlecock bagi masyarakat desa Pulesari merupakan mata pencaharian yang dapat diandalkan untuk menunjang kehidupan sehari-hari. Kondisi ini dapat dipakai sebagai bagian dari cara untuk mengurangi angka kemiskinan, karena berdasarkan hasil survei yang telah dilakukan tahun 2016 angka kemiskinan kabupaten Malang sudah mencapai 11,49 persen (https://news.detik.com/berita-jawa-timur/d-3692342/ minimnya-lapangan-pekerjaan-inijumlah-kemiskinan-kabupaten-malang/komentar). Sedangkan di desa Pulesari dapat dipotret ada sekitar 17 industri shuttlecock yang dapat membantu pemerintah dalam mengurangi tingkat pengangguran yang masih cukup tinggi yaitu sebesar Rp. 294904 per kapita per bulan per orang tahun 2017 (https://malangkab.bps.go.id/statictable/2016/08/01/477/ garis-kemiskinan-danpenduduk-miskin-di-kabupaten-malang-2011---2017.html).

Melalui pemberdayaan masyarakat secara berkelanjutan akan mampu peningkatan ketrampilan dan kemampuan sendiri untuk membuka usaha dan dapat membantu pemerintah dalam penyerapan tenaga kerja serta dapat meningkatkan kemampuan ekonomi lokal dan dapat mengurangi pengangguran dan angka kemiskinan di Kabupaten Malang sehingga bisa turun menjadi 9 persen pada tahun 2018. (https://malang.merdeka.com/kabar-malang/target-2018angka-kemiskinan-kabupaten-malang-turun-jadi-9-persen-170823q.html).

Menurut Mulyanto (2001), bahwa sebagian dari masyarakat di pedesaan biasanya berkembang melalui pemikiran yang penuh dengan upaya untuk memperoleh pendapatan agar bisa memenuhi kebutuhan rumah tangga. Sebagian besar masalah mendasar dari para pemilik usaha kecil yang paling menonjol pada ketersediaan modal. Sedangkan kebutuhan modal sangat dirasakan pada saat seseorang ingin memulai usaha baru. Motivasi juga akan mempengaruhi dalam menjalankan usaha kecil namun tidak terlalu mendasar dalam melanjutkan operasi usahanya. Disamping itu, pasar, pengelolaan manajemen, dan akses informasi juga sesuatu hal penting yang harus diperhatikan dalam memulai usaha.

Industri shuttlecock desa Pulesari Tirtomoyo ini terus berkembang, hal ini dikarenakan adanya permintaan shuttlecock dari konsumen terus meningkat dan menjadikan usaha ini sangat potensi dimasa yang akan datang. Disamping itu minat masyarakat Indonesia terhadap olahraga bulutangkis terus meningkat dimulai dari anak-anak, remaja, orang dewasa sampai orang tua. Olahraga bulutangkis dapat dimainkan baik didalam maupun di luar ruangan. Subarjah (2009), bulutangkis sebagai olahraga permainan telah berkembang dari dahulu sampai sekarang, dan terus berkembang sebagai olahraga yang menarik dengan tujuan baik untuk kebugaran, pemenuhan kebutuhan rekreasi, peningkatan prestasi sekaligus pemenuhan kebutuhan ekonomi, prestise dan bulutangkis sebagai salah satu cabang olahraga permainan yang popular dan digemari oleh masyarakat Indonesia yang menyenangkan, sebagai sarana rekreasi dan kompetisi bergengsi baik di dalam maupun diluar negeri. Olahraga bulutangkis mampu mengharumkan negara Indonesi di mata dunia.

Shuttlecock berupa bola yang dimanfaatkan untuk olahraga bulutangkis, bahan baku yang digunakan berupa bulu unggas, gabus, benang dan lem. Gabus sebagian besar pasarnya $80 \%$ didominasi oleh Korea Selatan dan Thailand. Di Kota Malang bahan baku bulu angsa dapat diperoleh dari Singosari Kabupaten Malang melalui importir. Tidak semua bulu unggas dapat digunakan sebagai bahan baku untuk produksi shuttlecock. Gabus bagian dari bahan baku pembuatan shuttlecock juga menjadi penting selain akan mempengaruhi berat shuttlecock juga sebagai tempat bulu angsa ditancapkan, gabus dapat dibeli dari agen, menurut kebiasaan, agen tersebut akan membeli kembali hasil produksi shuttlecock yang sudah jadi. Bahan penolong dari shuttlecock adalah kardus, ticket, plastik, pita, dan lem. 
Bulutangkis di beberapa sekolah dijadikan andalan sebagai pilihan ekstrakulikuler, karena olahraga yang menggunakan shuttlecock dan raket sehingga mampu memberikan motivasi dan memusatkan perhatian pada sasaran yang jelas, serta kekuatan pukulan akan mempengaruhi kecepatan shuttlecock menurut Tsai, Huang, and Jih (2005). Abe dan Izard (dalam Gunarsa, 2004) kecerdasan emosional bisa dilatih dan berkembang, salah satunya dengan kegiatan olahraga terutama olahraga yang dilakukan dalam kelompok seperti olahraga disekolah. Menurut Maman (2005) dan Goleman (2004) melalui ekstrakulikuler olahraga dapat membiasakan siswa terampil mengorganisasi, mengelola, menambah wawasan, memecahkan masalah dan pandai menyesuaikan diri dengan suasana hati orang lain maka orang tersebut memiliki tingkat emosionalitas yang baik.

Usaha shuttlecock milik bapak Khoirul desa Pulesari mempunyai pangsa pasar yang cukup luas mulai dari Malang Raya sampai ke luar pulau jawa (Kalimantan, Sumatera). Usaha yang dirintis bapak Khoirul dapat membuka peluang usaha untuk orang lain, hal ini dapat diketahui dari jumlah tenaga kerja yang dimiliki sejumlah \pm 10 orang. Sedangkan usaha bapak Ridwan merupakan produsen shuttlecock yang lumayan besar dibandingkan usaha bapak Khoirul karena mempunyai karyawan $\pm 15-20$ orang dan jumlah produksinya sudah mencapai 2.000 slop dalam satu bulan. Pangsa pasarnya juga lumayan luas mulai jawa sampai luar pulau yaitu: Sumatera, Kalimantan, Jakarta, Surabaya, dan Malang Raya. Permintaan pasar akan shuttlecock yang paling banyak dari Jakarta, Sumatera, Kalimantan, dan sekitar Malang Raya. Peluang bisnis ini masih memungkinkan untuk dibuka lebih luas lagi karena jumlah permintaan terus bertambah namun belum dapat terpemuhi. Kondisi ini disebabkan oleh manajemen lemah, kapasitas produksi terbatas, minimnya peralatan yang dimiliki, jumlah karyawan, bahan baku yang mulai sulit diperoleh karena mengandalkan dari seorang importir dari singosari dan harga terus naik.

\section{METODE}

Metode yang dapat dipilih untuk menyelesaikan permasalahan mitra dalam usaha shuttlecock adalah dengan merancang desain dan membuatkan mesin eluk bulu angsa. Fungsi dari mesin tersebut adalah untuk meluruskan bulu angsa yang akan di tempelkan dalam gabus untuk shuttlecock, sehingga harus memiliki standar khusus dari bulu yang akan dijadikan shuttle cock. Oleh karena itu, shuttlecock dibuat didasarkan dari ketentuan bulu tangkis dunia atau Badan Federasi Bulutangkis Dunia (BWF) maka bulu angsa yang akan digunakan harus diluruskan terlebih dahulu, hal ini dikarenakan akan dapat mempengaruhi pada kecepatan shuttlecock. Sedangkan bentuk shuttlecock yang standar terdiri dari beberapa bagian ukuran (http://produksishutlecock.blogspot.com/2016/04/produksi-shutltecock.html).

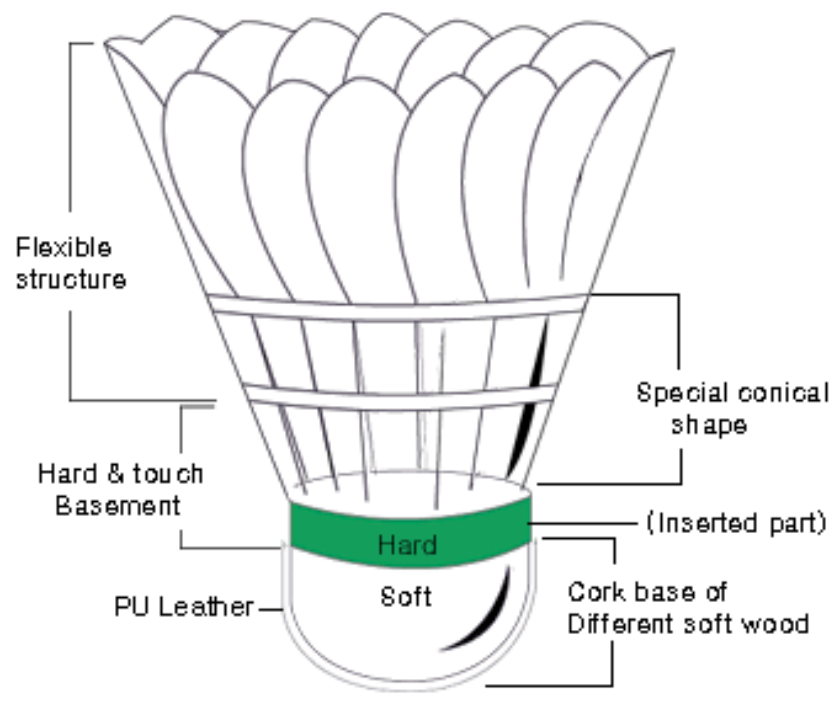

Gambar 1. Bentuk standar shuttlecock 
Menurut hukum dan aturan dari BWF bahwa karakteristik shuttlecock meliputi: memiliki 16 buah bulu, bulu harus memiliki panjang yang sama yaitu antara $62 \mathrm{~mm}$ dan $70 \mathrm{~mm}$, ujung dari bulu-bulu harus membentuk lingkaran dengan panjang diameter antara $58 \mathrm{~mm}$ dan $68 \mathrm{~mm}$, semua bulu harus tergabung menjadi satu kesatuan yang kuat, pangkal kok yang berbentuk setengah bola harus memiliki panjang diameter antara $25 \mathrm{~mm}$ dan $28 \mathrm{~mm}$, berat kok seluruhnya harus antara 4,47 gram dan 5,50 gram.

Shuttlecock yang berkualitas dan bagus menggunakan bahan baku dari bulu angsa berkualitas, putih, ulet dan tebal. Bulu angsa melalui proses pengukusan dan pengeringan akan mekar sehingga tidak mudah rontok dan patah. Ujung bulu angsa dipotong lancip akan menghasilkan shuttlecock yang berputar (berotasi) saat dipukul. Kepala cock dari gabus yang kuat, empuk tidak mudah pecah, tidak cepat gepeng kalau dipukul, tidak mudah rontok bulu angsanya dan harus berkualitas. Berdasarkan aturan kecepatan (speed) shuttlecock rata-rata 78 (bisa berkisar antara 77 - 78). Sedangkan berat shuttlecock rata-rata 4,9 gr (bisa berkisar antara 4,8 gr - 51 gr). Kecepatan pukulan shuttlecock dipengaruhi oleh kelembaban udara, temperatur dan ukuran lapangan. Shuttlecock juga memiliki kecepatan rotasi agar tetap stabil yaitu dengan kecepatan lebih dari 0,65 Mach $(0,65 \times$ kecepatan suara $)$, kecepatan suara $=330 \mathrm{~m} / \mathrm{s}$, bulu angsa paling atas melengkung dari rata-rata posisi 11,8 derajat ke 20 derajat atau lebih dari permukaan tubuhnya.

Tahapan dari metode pembuatan mesin eluk bulu adalah menentukan mitra, memecahkan masalah mitra, adanya kesepakatan mesin yang akan didesain, merancang desain mesin, pembuatan ke bengkel mesin, uji coba mesin, koreksi mesin jika belum sempurna, uji coba lagi dan kalau sudah sesuai dengan harapan dari mesin eluk bulu ini maka tahapan akhir adalah menyerahkan ke mitra. Adapun tahapan dari metode pelaksanaan pengabdian masyarakat untuk membuat mesin eluk bulu dapat dilihat pada gambar 2 sebagai berikut:

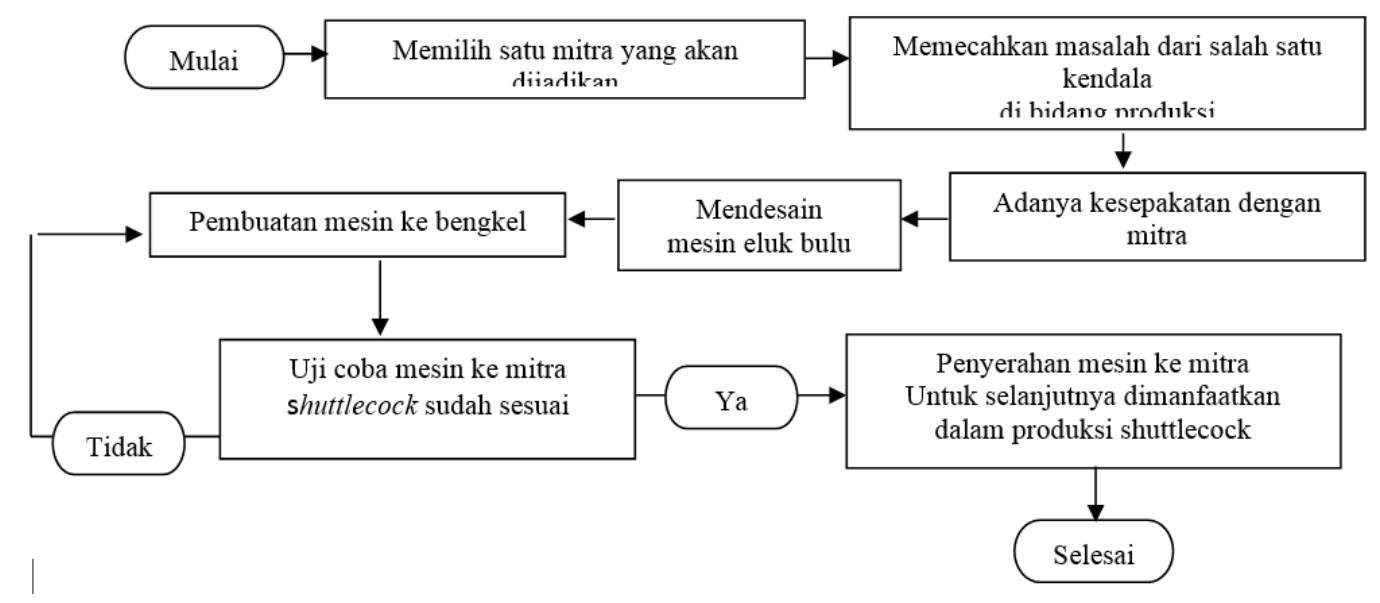

Gambar 2: tahapan dalam metode pelaksanaan pengabdian masyarakat untuk mesin eluk bulu

\section{HASIL DAN PEMBAHASAN}

1. Desain mesin eluk bulu angsa yang mempunyai fungsi untuk meluruskan bulu mempunyai spesifikasi ukuran panjang $75 \mathrm{~cm}$, lebar $60 \mathrm{~cm}$, tinggi $50 \mathrm{~cm}$. Disain mesin eluk bulu bisa dilihat dari tampak atas, belakang dan depan. Penggerak mesin dengan dinamo listrik berukuran $1 \mathrm{pk}$, dengan daya 250 watt, voltase 220. Mesin dibuat dari dua sisi yaitu kanan dan kiri, hal ini dilakukan karena bulu angsa ada yang bengkok ke kiri dan ada yang bengkok ke kanan. Adapun bentuk disain mesin eluk bulu dapat dilihat pada gambar 3 dan gambar 4 sebagai berikut: 
Jurnal Aplikasi dan Inovasi Ipteks, Vol. 1 / No. 1 / April 2018 ; 1-10

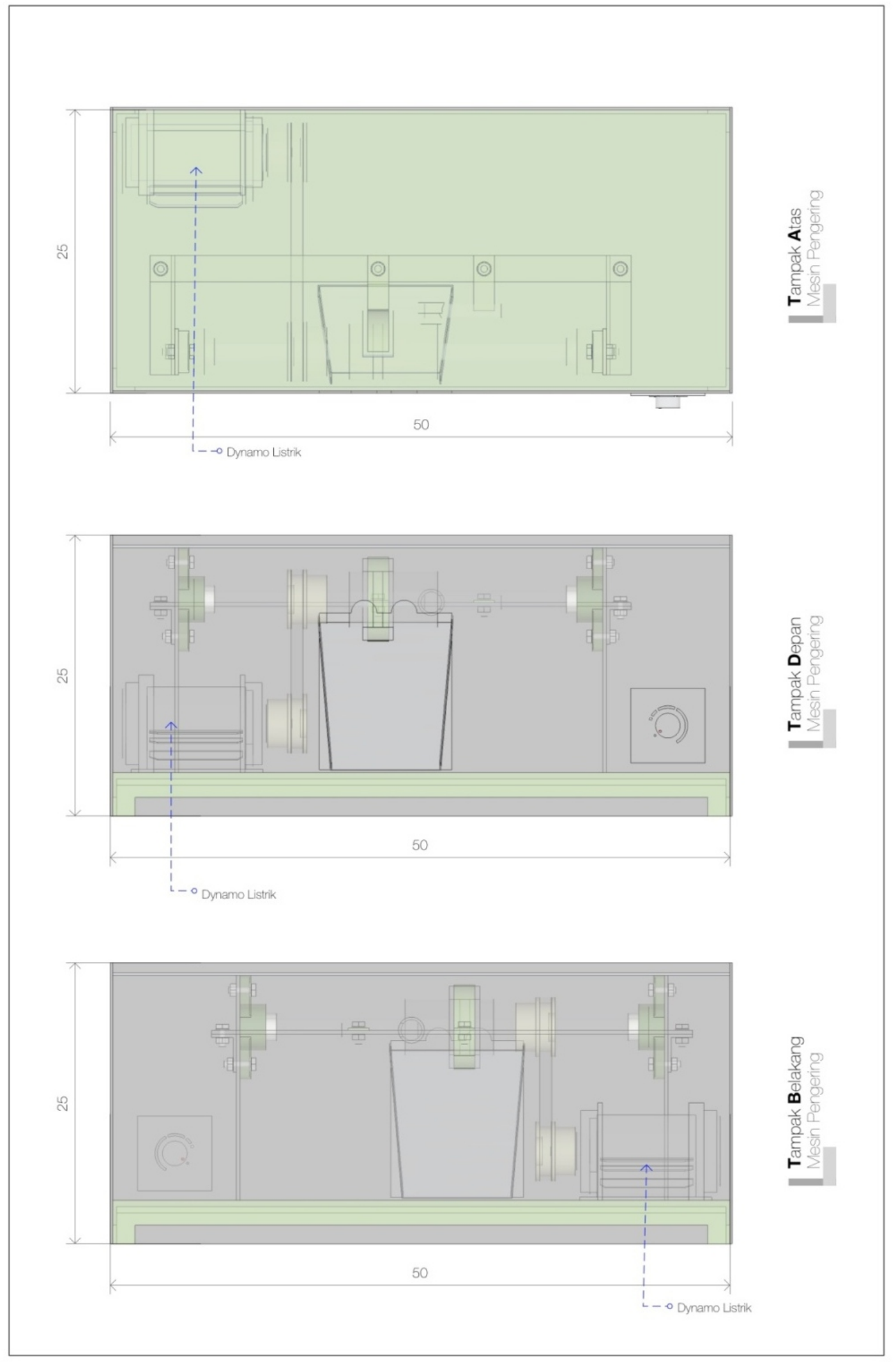

Gambar 3 : disain mesin eluk bulu tampak belakang, depan dan atas 


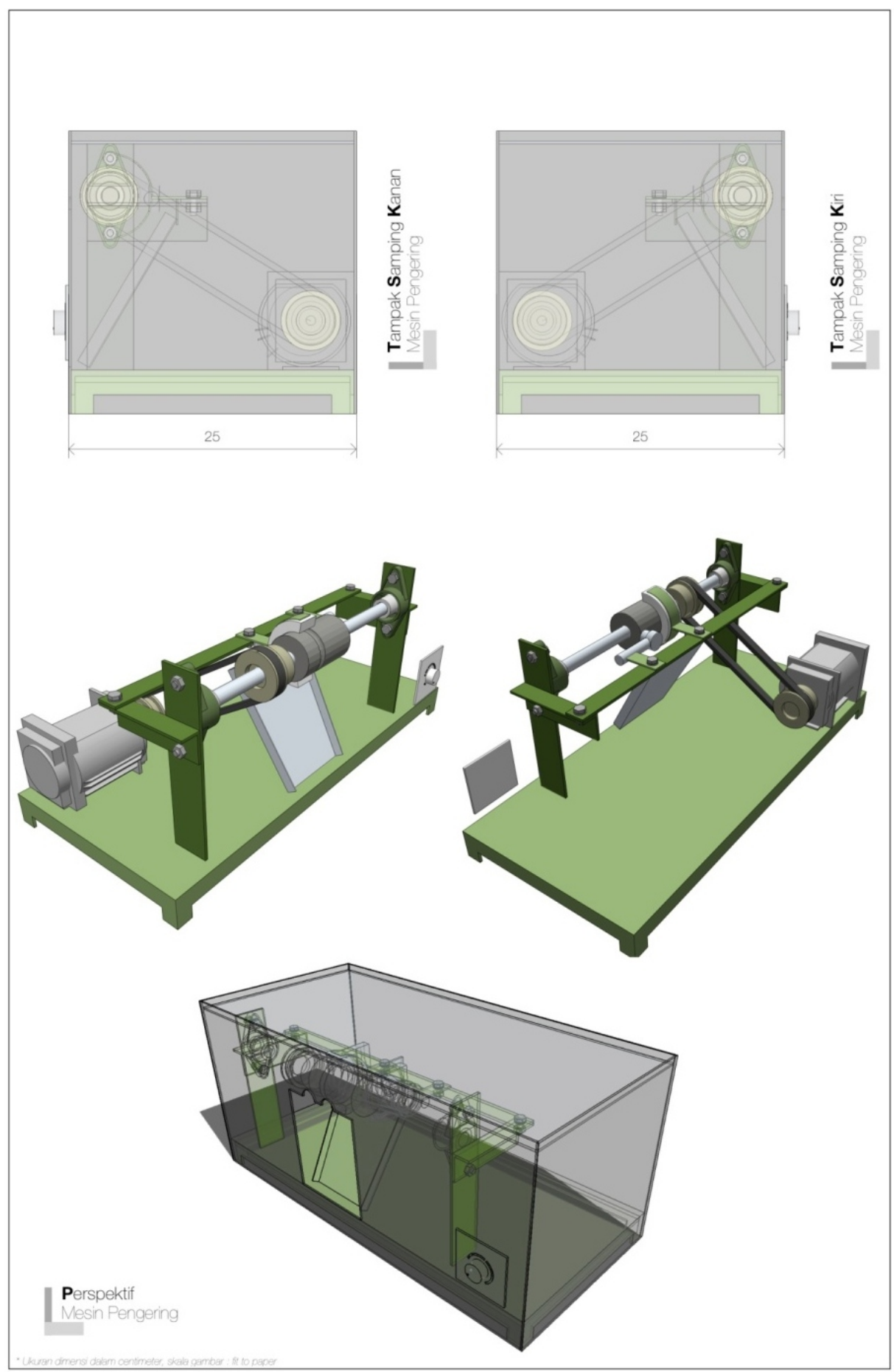

Gambar 4: detail desain mesin eluk bulu

2. Bentuk mesin eluk bulu sebagai bentuk fisik yang bisa langsung difungsikan sebagai pelurus bulu angsa akan mampu menghasilkan bulu angsa lurus dalam 1 menit \pm 100 bulu sedangkan sebelumnya hanya berkisar 32 bulu dalam 1 menit. Hasil 1 shuttle cock terdiri dari 16 bulu angsa diperlukan waktu $1 / 2$ menit atau dalam 1 menit menghasilkan 32 bulu angsa lurus. Mesin eluk bulu angsa sebagai teknologi tepat guna dalam 1 menit menghasilkan sebanyak 100 bulu atau \pm 8 slop shuttle cock, dan masih ada kelebihan 3 cock. 1 slop 12 shuttle cock dengan harga Rp. 54.000,dan sisa 3 shuttle cock $\mathrm{x}$ Rp. $4.500=\mathrm{Rp}$ 13.500,- oleh karena itu pemanfaatan teknologi mampu memberikan kemudahan bagi usaha kecil dalam meningkatkan usaha. Inovasi mesin eluk bulu 
angsa dapat memberikan efisiensi waktu dan biaya, sedangkan kenaikan hasil produksi shuttle cock dalam 1 menit sebesar 312,5\%. Adapun perbedaan antara bentuk fisik proses pelurusan bulu angsa secara manual dengan tang dan setelah dengan mesin eluk bulu dapat dilihat pada gambar 5, gambar 6 dan gambar 7 sebagai berikut:

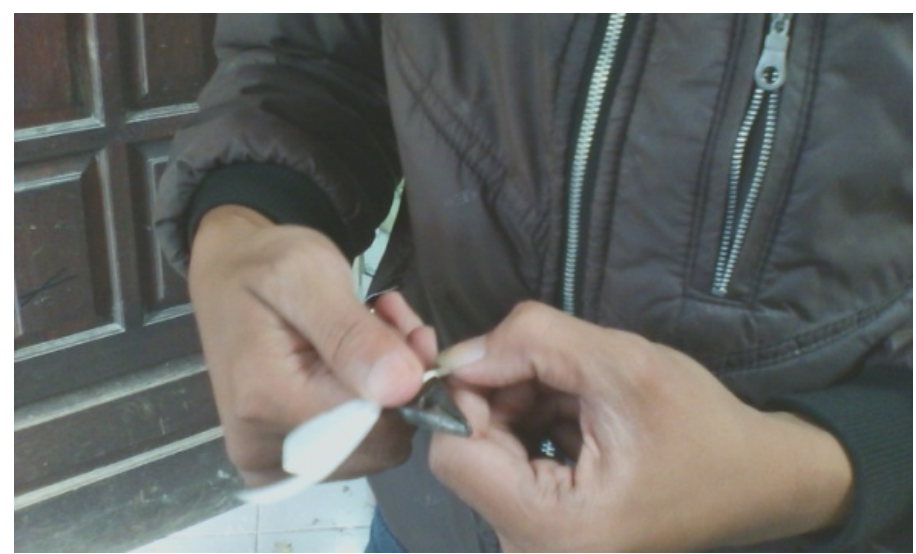

Gambar 5: proses eluk bulu atau pelurusan bulu angsa dengan cara manual memakai tang

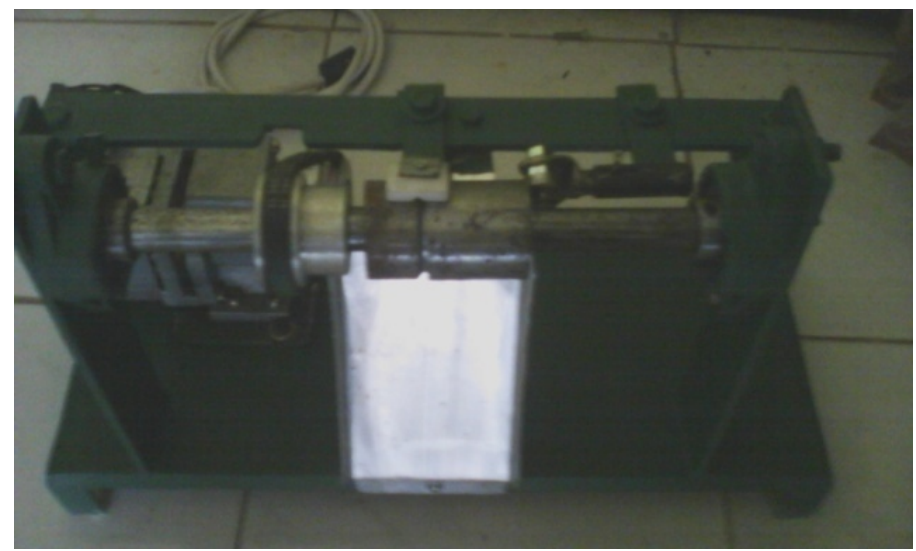

Gambar 6: dalam mesin eluk bulu atau pelurusan bulu angsa dengan model rotary

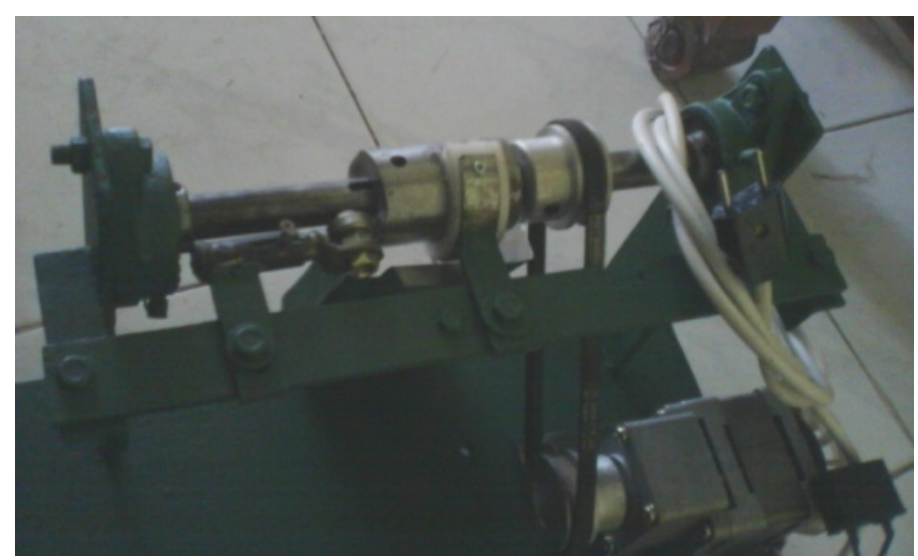

Gambar 7: fisik mesin eluk bulu atau pelurusan bulu angsa tampak depan

3. Penyerahan mesin ke mitra merupakan salah satu kewajiban pelaksana pengabdian agar secara resmi mesin tersebut harus bisa dimanfaatkan sebaik mungkin dan dirawat sebagai salah satu aset yang telah memberikan kemudahan dalam produksi shuttlecock sesuai dengan gambar 8 . 


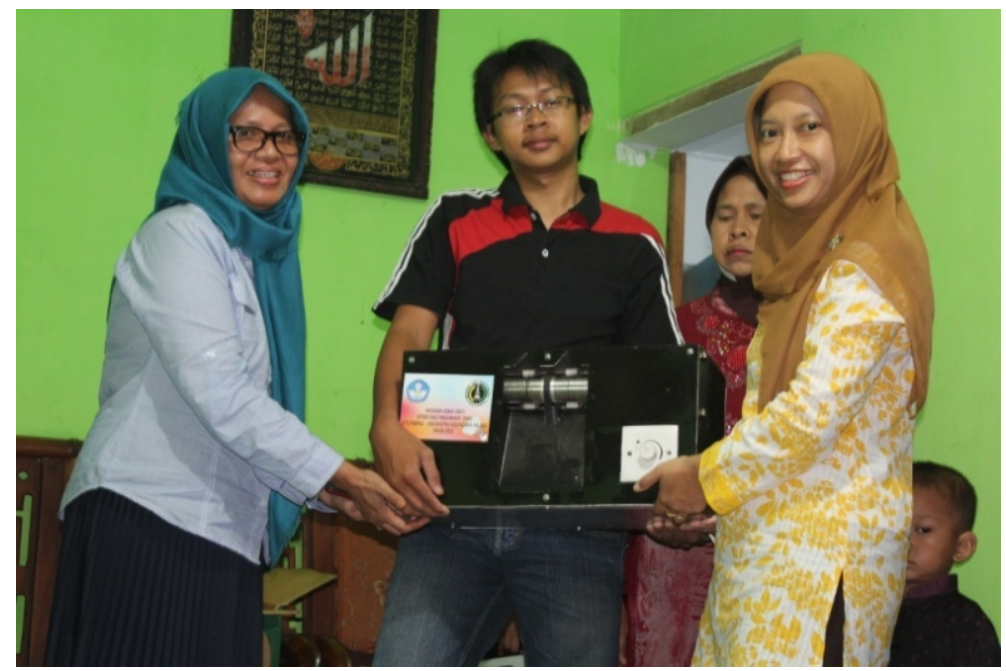

Gambar 8: penyerahan mesin eluk bulu ke mitra sebagai obyek untuk pengabdian masyarakat

4. Monitoring dalam pelaksanaan pengabdian masyarakat telah dilakukan oleh Tim dari LPPM Universitas Widyagama Malang sebagai bentuk evaluasi dari kegiatan tyang telah dilakukan di masyarakat dan ketepatan sasaran bagi pemanfaatan mesin yang telah di berikan ke mitra dalam hal ini bisa dilihat pada gambar 9:

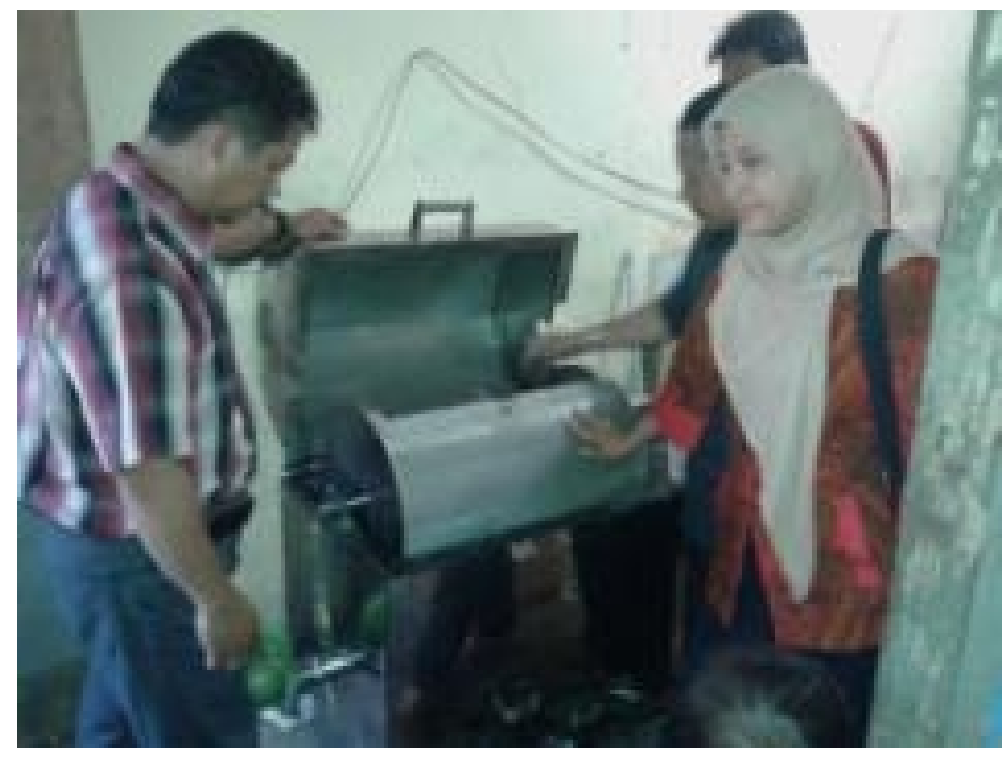

Gambar 9: monitoring oleh tim LPPM Universitas Widyagama Malang

\section{DAMPAK DAN MANFAAT}

Kegiatan pengabdian masyarakat ini telah memberikan manfaat bagi mitra untuk menambah wawasan dalam pemanfaatan teknologi yang berdampak pada efisiensi waktu, biaya tanaga kerja, hasil produksi lebih cepat dan bulu angsa yang dihasilkan lebih standart sesuai dengan persyarakat dari BWF. Pendapatan yang diperoleh menjadi lebih besar dalam 1 bulan mampu menghasilkan shuttlecock sesuai dengan penjualan shuttlecock 16 karton x 60 slop x Rp.54.000,dalam 1 bulan sebesar $=$ Rp. 51.840.000,-. Sedangkan keuntungan yang diperoleh setelah dikurangi dengan biaya operasional usaha sebesar Rp. 5.417.200,-. 
Jurnal Aplikasi dan Inovasi Ipteks, Vol. 1 / No. 1 / April 2018 ; 1-10

\section{KESIMPULAN}

1. Menghasilkan desain mesin eluk bulu angsa yang fungsinya sebagai pelurus bulu angsa dengan inovasi teknologi yang lebih baik dan sebagai pemanfaatan teknologi memberikan kemudahan, kecepatan dan hasil produk yang lebih standar sesuai dengan atauran dari BWF.

2. Efisiensi waktu dan pengurangan biaya produksi mampu memberikan keuntungan dalam 1 bulan sebesar Rp. 5.417.200,-. Penghasilan tersebut telah memberikan kehidupan bagi pemilik usaha rumahan yang cukup untuk biaya hidup, sekolah dan rekreasi. Disamping itu efisiensi waktu dan biaya mampu menaikkan hasil produksi shuttle cock dalam 1 menit sebesar $312,5 \%$.

3. Mesin eluk bulu memberikan inovasi dalam meluruskan bulu angsa yang dapat ditularkan pada pemilik usaha sejenis.

\section{UCAPAN TERIMAKASIH}

1. DRPM Kemenristekdikti yang telah memberikan kesempatan kepada kami dalam pemberian daha hibah pengabdian kepada masyarakat

2. Kopertis Wilayah VII yang telah membantu dalam proses kontrak dan pencairan dana serta pelaporan akhir.

3. Universitas Widyagama Malang yang telah memberikan kesempatan dalam keikutsertaan kami sebagai dosen dalam mewujudkan Tridharma Perguruan Tinggi.

4. Dekan dan LPPM yang telah memberikan kemudahan proses administrasi dalam pelaksanaan pengabdian kepada masyarakat.

\section{REFERENSI}

Biro Pusat Statistik (2017). Garis Kemiskinan dan Penduduk Miskin di Kabupaten Malang, 2011 2017 https://malangkab.bps.go.id/statictable/2016/08/01/477/garis-kemiskinan-danpenduduk-miskin-di-kabupaten-malang-2011---2017.html.

Gerbang Industri Kota Tega 1,2016 . Produksi shutt lecock, http://produksishutlecock.blogspot.com/2016/04/produksi-shutltecock.html. 16 April 2016

Goleman, D. (2004). Emotional Intelligence. Alih bahasa: Hermaya, T. Jakarta: PT Gramedia Pustaka Utama.

Gunarsa, S. D. (2004). Psikologi Olahraga Prestasi. Jakarta: PT. BPK Gunung Mulia.

Maman. (2005). Ekstrakurikuler Sebagai Pembelajaran Alternatif.

Muhammad Aminudin - detikNews, (2017).. Minimnya Lapangan Pekerjaan, Ini Jumlah

Kemiskinan Kabupaten Malang, https://news.detik.com/berita-jawa-timur/d-

3692342/minimnya-lapangan-pekerjaan-ini-jumlah-kemiskinan-kabupaten-

malang/komentar Jumat 20 Oktober 2017, 11:32 WIB

Siti Rutmawati. (2017). https://malang.merdeka.com/kabar-malang/target-2018-angkakemiskinan-kabupaten-malang-turun-jadi-9-persen-170823q.html. Rabu, 23 Agustus 2017 17:12

Subarjah, H. (2009). Permainan bulutangkis. Bandung: FPOK UPI

Sumardi Mulyanto, (2001). Kemiskinan dan Kebutuhan Pokok, Rajawali, Jakarta. Tarsis, Tarmudji, 1991 , Manusia Wiraswasta, IKIP Semarang Press, Semarang. http://www.Pembinaan+industri+kecil+dan+menengah

Tsai, C.L, Yang. C.C, Lin. M.S, Huang. K.S. (2005). “The Surface EMG Actifity Analysis Between Badminton Smash And Jump Smash”. Journal Of Biomechanics In Sport.483- 487. 